\title{
High-entropy Alloys Fabricated Through Powder Metallurgy for Low-temperature Applications
}

Luis Laguna Zubia ${ }^{1}$, C.G. Garay-Reyes ${ }^{2}$, M.A. Rascón-Sánchez ${ }^{3}$, Ivanovich Estrada ${ }^{4}$, J.P. Flores-De-losRíos $^{3}$, R. Martínez-Sánchez ${ }^{2}$, A. Caro-Duran ${ }^{5}$, M.C. Maldonado-Orozco ${ }^{5}$, P.A. Guerrero-Seáñez ${ }^{5}$ and M.A. Ruiz-Esparza-Rodriguez ${ }^{2}$

${ }^{1}$ Universidad Autónoma de Chihuahua, Facultad de Ingeniería., Meoqui, Chihuahua, Mexico, ${ }^{2}$ Centro de Investigación en Materiales Avanzados (CIMAV), Laboratorio Nacional de Nanotecnología, Chihuahua, Chihuahua, México, ${ }^{3}$ Universidad Autónoma de Chihuahua, Facultad de Ingeniería., Chihuahua, Chihuahua, Mexico, ${ }^{4}$ Centro de Investigacion en Materiales Avanzados SC, Chihuahua, Chihuahua, Mexico, ${ }^{5}$ Universidad Autónoma de Chihuahua, Chihuahua, Chihuahua, Mexico

Current High-Entropy Alloys (HEAs) were born from the similarities of the multi-component alloys proposed by B. Cantor et. al.[1] and high-entropy alloys proposed by J. W. Yeh et. al.[2]. The HEAs are systems formed with at least 5 elements in an equiatomic composition or near equiatomic with a proportion less than 35 at\%; besides, they need to reach the entropy of $1.5 \mathrm{R}$, where $\mathrm{R}$ is the ideal gas constant. Unlike traditional metallurgical casting routes, powder metallurgical routes are favorable because it has much lower temperatures for material consolidation. However, most HEAs require relatively high sintering temperatures, so developing thermodynamically stable alloy powders that are susceptible to sintering at relatively low-temperatures $\left(\sim 500^{\circ} \mathrm{C}\right)$ will open a new field of study.

The raw powders for fabricating the systems to study were aluminum at $99.5 \%$ of purity, copper at $99.5 \%$ of purity, nickel at $99.9 \%$ of purity, tin at $99.8 \%$ of purity, and zinc at $99.9 \%$ of purity. The millings were made in a Spex $8000 \mathrm{M}$ Mill by 10 hours, adding $1 \mathrm{ml}$ of $\mathrm{n}$-Heptane as a process control agent and under argon controlled atmosphere. Two systems, (AlCuNi)80Sn10Zn10 and (AlCuNi)70Sn15Zn15, were obtained. The container and the miller balls employed were made of hardened steel; the relation weighs between the balls, and the powders were 5:1. By X-Rays Diffraction (XRD) and Transmission Electron Microscopy (TEM) were characterized the crystalline structure of powders. All samples were prepared using conventional micrographic technics.

Phase predictions corresponding to $\delta \mathrm{r} / \Delta \mathrm{H}_{\mathrm{mix}}, \mathrm{VEC}$, and e/a are presented in Figure 1 , where $\delta \mathrm{r}$ is the difference of atomic ratio; $\Delta \mathrm{H}_{\text {mix }}$ is the enthalpy of the system; VEC is valence electron concentration and e/a is electron per atom. The predictions showed a multiphasic BCC-FCC structure, an FCC structure, and a BCC structure for $\delta \mathrm{r} / \Delta \mathrm{H}_{\mathrm{mix}}, \mathrm{VEC}$, and e /a, respectively. However, analysis by XRD and TEM-SAED shows that the powders are multiphasic; both systems present a stable BCC and FCC crystalline structures how it is presented in Figure 2.

\begin{tabular}{|c|c|c|}
\hline \multicolumn{3}{|c|}{ Phase prediction } \\
\hline & $(\mathrm{AlCuNi})_{70} \mathrm{Sn}_{15} \mathbf{Z n}_{15}$ & $(\mathrm{AlCuNi})_{80} \mathbf{S n}_{10} \mathbf{Z n}_{10}$ \\
\hline $\mathrm{e} / \mathrm{a}$ & $\mathrm{BCC}$ & $\mathrm{BCC}$ \\
\hline VEC & $\mathrm{FCC}$ & $\mathrm{FCC}$ \\
\hline $\boldsymbol{\delta}_{\mathrm{r}} / \Delta \mathrm{H}_{\text {mix }}$ & $\mathrm{BCC} / \mathrm{FCC}$ & $\mathrm{BCC} / \mathrm{FCC}$ \\
\hline
\end{tabular}

Figure 1. Phase prediction corresponding to $\delta \mathrm{r} / \triangle \mathrm{Hmix}, \mathrm{VEC}$, and e/a 

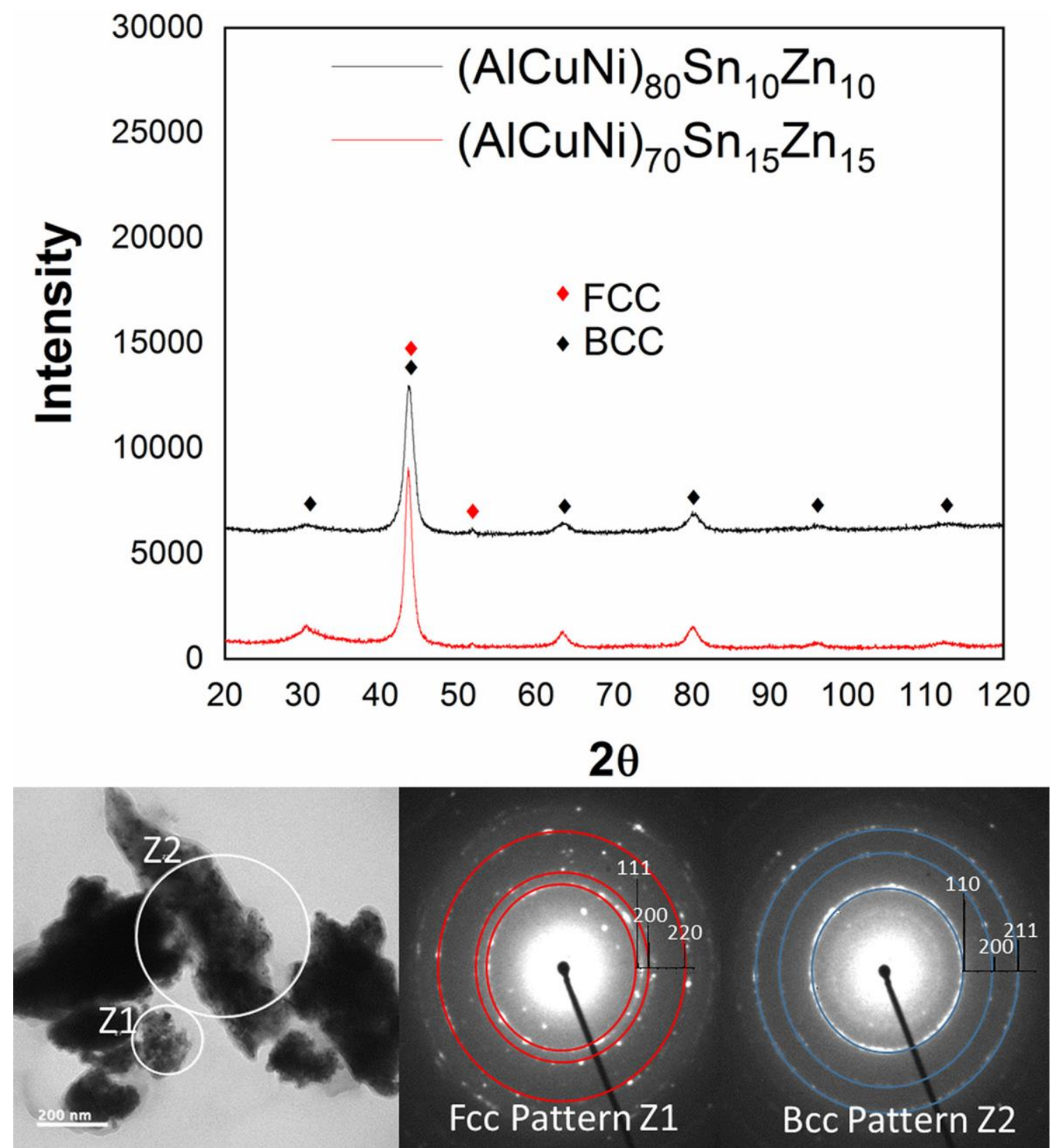

Figure 2. XRD patterns corresponding to (AlCuNi)80Sn10Zn10 and (AlCuNi)70Sn15Zn15, and TEM Micrograph and corresponding SAED of (AlCuNi)70Sn15Zn15 system

\section{References}

[1]B. Cantor, I.T.H. Chang, P. Knight, A.J.B. Vincent Mater. Sci. Eng. A, 375-377 (2004), pp. 213-218 https://doi.org/10.1016/j.msea.2003.10.257

[2]J.W. Yeh, S.K. Chen, S.J. Lin, J.Y. Gan, T.S. Chin, T.T. Shun, C.H. Tsau, S.Y. Chang Nanostructured high-entropy alloys with multiple principal elements: Novel alloy design concepts and outcomes. Adv. Eng. Mater., 6 (2004), pp. 299-303 https://doi.org/10.1002/adem.200300567 